\title{
Research Article \\ Strong Convergence Theorem for Two Commutative Asymptotically Nonexpansive Mappings in Hilbert Space
}

\author{
Jianjun Liu, Lili He, and Lei Deng \\ School of Mathematics and Statistics, Southwest University, Chongqing 400715, China
}

Correspondence should be addressed to Jianjun Liu, liliu@swu.edu.cn

Received 20 June 2008; Accepted 8 December 2008

Recommended by Enrico Obrecht

$C$ is a bounded closed convex subset of a Hilbert space $H, T$ and $S: C \rightarrow C$ are two asymptotically nonexpansive mappings such that $S T=T S$. We establish a strong convergence theorem for $S$ and $T$ in Hilbert space by hybrid method. The results generalize and unify many corresponding results.

Copyright (C) 2008 Jianjun Liu et al. This is an open access article distributed under the Creative Commons Attribution License, which permits unrestricted use, distribution, and reproduction in any medium, provided the original work is properly cited.

\section{Introduction}

Let $C$ be a bounded closed convex subset of a Hilbert space $H$. Recall that a mapping $T: C \rightarrow$ $C$ is said to be asymptotically nonexpansive mapping if

$$
\left\|T^{n} x-T^{n} y\right\| \leq t_{n}\|x-y\| \quad \forall x, y \in C,
$$

where $t_{n} \rightarrow 1(n \rightarrow \infty)$. We may assume that $t_{n} \geq 1$ for all $n=1,2,3, \ldots$ Denote by $F(T)$ the set of fixed points of $T$. Throughout this paper $T$ and $S: C \rightarrow C$ are two commutative asymptotically nonexpansive mappings with asymptotical coefficients $\left\{t_{n}\right\}$ and $\left\{s_{n}\right\}$, respectively. Suppose that $F:=F(T) \cap F(S) \neq \varnothing([1$, Goebel and Kirk's theorem $]$ makes it possible). It is well known that $F(T)$ and $F(S)$ are convex and closed $[1,2]$, so is $F . P_{K}$ denotes the metric projection from $H$ onto a closed convex subset $K$ of $H$ and $\omega_{w}\left(x_{n}\right)$ denotes the weak $w$-limit set of $\left\{x_{n}\right\}$. It is well known that a Hilbert space $H$ satisfies Opial's condition [3], that is, if a sequence $\left\{x_{n}\right\}$ converges weakly to an element $y \in H$ and $y \neq z$, then

$$
\liminf _{n \rightarrow \infty}\left\|x_{n}-y\right\|<\liminf _{n \rightarrow \infty}\left\|x_{n}-z\right\|
$$


Up to now, fixed points iteration processes for nonexpansive and asymptotically nonexpansive mappings have been studied extensively by many authors to solve nonlinear operator equations as well as variational inequalities [4-6]. There are many strong convergence theorems for nonexpansive and asymptotically nonexpansive mappings in Hilbert space $[7,8]$.

Especially, Shimizu and Takahashi [7] studied the following iteration process of nonexpansive mappings for arbitrary $x_{0} \in C$ :

$$
x_{n+1}=\alpha_{n} x_{0}+\left(1-\alpha_{n}\right) \frac{2}{(n+1)(n+2)} \sum_{k=0}^{n} \sum_{i+j=k} S^{i} T^{j} x_{n}
$$

where $\left\{\alpha_{n}\right\} \subseteq[0,1], \lim _{n \rightarrow \infty} \alpha_{n}=0, \sum_{n=0}^{\infty} \alpha_{n}=\infty$. And then they proved that $\left\{x_{n}\right\}$ converges strongly to $P_{F}\left(x_{0}\right)$. This result was extended to two commutative asymptotically nonexpansive mappings by Shioji and Takahashi [9].

Recently, some attempts to the modified Mann iteration method are made so that strong convergence is guaranteed. And for hybrid method proposed by Haugazeau [10], Kim and $\mathrm{Xu}[8]$ introduced the following iteration processes for asymptotically nonexpansive mapping $T$ :

$$
\begin{aligned}
x_{0} & \in C \text { chosen arbitrarily, } \\
y_{n} & =\alpha_{n} x_{n}+\left(1-\alpha_{n}\right) T^{n} x_{n}, \\
C_{n} & =\left\{v \in C:\left\|y_{n}-v\right\|^{2} \leq\left\|x_{n}-v\right\|^{2}+\theta_{n}\right\}, \\
Q_{n} & =\left\{v \in C:\left\langle x_{n}-v, x_{0}-x_{n}\right\rangle \geq 0\right\}, \\
x_{n+1} & =P_{C_{n} \cap Q_{n}}\left(x_{0}\right),
\end{aligned}
$$

where $\theta_{n}=\left(1-\alpha_{n}\right)\left(t_{n}^{2}-1\right)(\operatorname{diam} C)^{2} \rightarrow 0$ as $n \rightarrow \infty$. Then proved that $\left\{x_{n}\right\}$ converges strongly to $P_{F}\left(x_{0}\right)$. This result was generalized to two asymptotically nonexpansive mappings by Plubtieng and Ungchittrakool [11].

On the basis of (1.3) and (1.4), we propose a new iteration processes for two commutative asymptotically nonexpansive mappings $S$ and $T$ :

$$
\begin{aligned}
x_{0} & \in C \text { chosen arbitrarily, } \\
y_{n} & =\alpha_{n} x_{n}+\left(1-\alpha_{n}\right) \frac{2}{(n+1)(n+2)} \sum_{k=0}^{n} \sum_{i+j=k} S^{i} T^{j} x_{n}, \\
C_{n} & =\left\{v \in C:\left\|y_{n}-v\right\|^{2} \leq\left\|x_{n}-v\right\|^{2}+\theta_{n}\right\}, \\
Q_{n} & =\left\{v \in C:\left\langle x_{n}-v, x_{0}-x_{n}\right\rangle \geq 0\right\}, \\
x_{n+1} & =P_{C_{n} \cap Q_{n}}\left(x_{0}\right),
\end{aligned}
$$

where $\theta_{n}=\left(1-\alpha_{n}\right)\left(g_{n}^{2}-1\right)(\operatorname{diam} C)^{2}, g_{n}=(2 /(n+1)(n+2)) \sum_{k=0}^{n} \sum_{i+j=k} s_{i} t_{j}$, for every $n=1,2, \ldots$. The purpose of this paper is to prove $\left\{x_{n}\right\}$ converges strongly to $P_{F}\left(x_{0}\right)$. 


\section{Auxiliary lemmas}

This section collects some lemmas which will be used to prove the main results in the next section.

Lemma 2.1 (see [7]). Letting $L_{n}=(n+1)(n+2) / 2$, there holds the identity in a Hilbert space $H$ :

$$
\left\|y_{n}-v\right\|^{2}=\frac{1}{L_{n}} \sum_{k=0}^{n} \sum_{i+j=k}\left\|x_{i, j}-v\right\|^{2}-\frac{1}{L_{n}} \sum_{k=0}^{n} \sum_{i+j=k}\left\|x_{i, j}-y_{n}\right\|^{2}
$$

for $\left\{x_{i, j}\right\}_{i, j=0}^{\infty} \subseteq H, y_{n}=\left(1 / L_{n}\right) \sum_{k=0}^{n} \sum_{i+j=k} x_{i, j} \in H$ and $v \in H$.

Lemma 2.2. Let $C$ be a bounded closed convex subset of a Hilbert space $H, S$ and $T$ two commutative asymptotically nonexpansive mappings of $C$ into itself with asymptotical coefficients $\left\{s_{n}\right\}$ and $\left\{t_{n}\right\}$, respectively. For any $x \in C$, put $F_{n}(x)=(2 /(n+1)(n+2)) \sum_{k=0}^{n} \sum_{i+j=k} S^{i} T^{j} x$. Then

$$
\begin{aligned}
& \lim _{l \rightarrow \infty} \limsup _{n \rightarrow \infty} \sup _{x \in C}\left\|F_{n}(x)-S^{l} F_{n}(x)\right\|=0, \\
& \lim _{l \rightarrow \infty} \limsup _{n \rightarrow \infty} \sup _{x \in C}\left\|F_{n}(x)-T^{l} F_{n}(x)\right\|=0 .
\end{aligned}
$$

Proof. Put $x_{i, j}=S^{i} T^{j} x, v=S^{l} F_{n}(x)$ and $L_{n}=(n+1)(n+2) / 2$. It follows from Lemma 2.1 that

$$
\begin{aligned}
\| F_{n}(x) & -S^{l} F_{n}(x) \|^{2} \\
= & \frac{1}{L_{n}} \sum_{k=0}^{n} \sum_{i+j=k}\left\|S^{i} T^{j} x-S^{l} F_{n}(x)\right\|^{2}-\frac{1}{L_{n}} \sum_{k=0}^{n} \sum_{i+j=k}\left\|S^{i} T^{j} x-F_{n}(x)\right\|^{2} \\
= & \frac{1}{L_{n}} \sum_{k=0}^{l-1} \sum_{i+j=k}\left\|S^{i} T^{j} x-S^{l} F_{n}(x)\right\|^{2}+\frac{1}{L_{n}} \sum_{k=l}^{n} \sum_{i+j=k, i \leq l-1}\left\|S^{i} T^{j} x-S^{l} F_{n}(x)\right\|^{2} \\
& +\frac{1}{L_{n}} \sum_{k=l}^{n} \sum_{i+j=k, i \geq l}\left\|S^{i} T^{j} x-S^{l} F_{n}(x)\right\|^{2}-\frac{1}{L_{n}} \sum_{k=0}^{n} \sum_{i+j=k}\left\|S^{i} T^{j} x-F_{n}(x)\right\|^{2} \\
\leq & \frac{1}{L_{n}} \sum_{k=0}^{l-1} \sum_{i+j=k}\left\|S^{i} T^{j} x-S^{l} F_{n}(x)\right\|^{2}+\frac{1}{L_{n}} \sum_{k=l}^{n} \sum_{i+j=k, i \leq l-1}\left\|S^{i} T^{j} x-S^{l} F_{n}(x)\right\|^{2} \\
& +\frac{1}{L_{n}} \sum_{k=l}^{n} \sum_{i+j=k, i \geq l} S_{l}^{2}\left\|S^{i-l} T^{j} x-F_{n}(x)\right\|^{2}-\frac{1}{L_{n}} \sum_{k=0}^{n} \sum_{i+j=k}\left\|S^{i} T^{j} x-F_{n}(x)\right\|^{2}
\end{aligned}
$$




$$
\begin{aligned}
= & \frac{1}{L_{n}} \sum_{k=0}^{l-1} \sum_{i+j=k}\left\|S^{i} T^{j} x-S^{l} F_{n}(x)\right\|^{2}+\frac{1}{L_{n}} \sum_{k=l}^{n} \sum_{i+j=k, i \leq l-1}\left\|S^{i} T^{j} x-S^{l} F_{n}(x)\right\|^{2} \\
& +\frac{1}{L_{n}} \sum_{k=0}^{n-l} \sum_{i+j=k} s_{l}^{2}\left\|S^{i} T^{j} x-F_{n}(x)\right\|^{2}-\frac{1}{L_{n}} \sum_{k=0}^{n} \sum_{i+j=k}\left\|S^{i} T^{j} x-F_{n}(x)\right\|^{2} \\
\leq & \frac{1}{L_{n}} \sum_{k=0}^{l-1} \sum_{i+j=k}\left\|S^{i} T^{j} x-S^{l} F_{n}(x)\right\|^{2}+\frac{1}{L_{n}} \sum_{k=l}^{n} \sum_{i+j=k, i \leq l-1}\left\|S^{i} T^{j} x-S^{l} F_{n}(x)\right\|^{2} \\
& +\frac{1}{L_{n}} \sum_{k=0}^{n-l} \sum_{i+j=k}\left(s_{l}^{2}-1\right)\left\|S^{i} T^{j} x-F_{n}(x)\right\|^{2} .
\end{aligned}
$$

Choose $p \in F$, then there exists a constant $M>0$ such that

$$
\begin{gathered}
\left\|S^{i} T^{j} x-p\right\| \leq s_{i} t_{j}\|x-p\| \leq \frac{M}{2}, \\
\left\|F_{n}(x)-p\right\| \leq \frac{1}{L_{n}} \sum_{k=0}^{n} \sum_{i+j=k}\left\|S^{i} T^{j} x-p\right\| \leq \frac{M}{2}, \\
\left\|S^{l} F_{n}(x)-p\right\| \leq s_{l}\left\|F_{n}(x)-p\right\| \leq \frac{M}{2},
\end{gathered}
$$

for all nonnegative integer $i, j, l$, and $n$. Hence, $\left\|S^{i} T^{j} x-S^{l} F_{n}(x)\right\| \leq M,\left\|S^{i} T^{j} x-F_{n}(x)\right\| \leq M$ for all nonnegative integer $i, j, l$, and $n$. So

$$
\begin{aligned}
& \sup _{x \in C}\left\|F_{n}(x)-S^{l} F_{n}(x)\right\|^{2} \\
& \quad \leq \frac{(l+1) l}{(n+2)(n+1)} M^{2}+\frac{2(n+1-l) l}{(n+2)(n+1)} M^{2}+\frac{\left(s_{l}^{2}-1\right)(n+2-l)(n+1-l)}{(n+2)(n+1)} M^{2} \\
& \quad \longrightarrow 0(n \longrightarrow \infty, l \longrightarrow \infty) .
\end{aligned}
$$

Similarly, we can prove

$$
\lim _{l \rightarrow \infty} \limsup _{n \rightarrow \infty} \sup _{x \in C}\left\|F_{n}(x)-T^{l} F_{n}(x)\right\|=0
$$

Remark 2.3. Lemma 2.2 extends [7, Lemma 1].

Lemma 2.4. Let $S$ and $T$ be two commutative asymptotically nonexpansive mappings defined on a bounded closed convex subset $C$ of a Hilbert space $H$ with asymptotical coefficients $\left\{s_{n}\right\}$ and $\left\{t_{n}\right\}$, respectively. Let $L_{n}=((n+1)(n+2) / 2)$. If $\left\{x_{n}\right\}$ is a sequence in $C$ such that $\left\{x_{n}\right\}$ converges weakly to some $x \in C$ and $\left\{x_{n}-\left(1 / L_{n}\right) \sum_{k=0}^{n} \sum_{i+j=k} S^{i} T^{j} x_{n}\right\}$ converges strongly to 0 , then $x \in F(S) \cap F(T)$. 
Jianjun Liu et al.

Proof. We claim that $\left\{S^{l} x\right\}$ converges strongly to $x$ as $l \rightarrow \infty$. If not, there exist a positive number $\varepsilon_{0}$ and a subsequence $\left\{l_{m}\right\}$ of $\{l\}$ such that $\left\|S^{l_{m}} x-x\right\| \geq \varepsilon_{0}$ for all $m$. However, we have

$$
\begin{aligned}
& \left\|x_{n}-S^{l_{m}} x\right\| \\
& \leq\left\|x_{n}-\frac{1}{L_{n}} \sum_{k=0}^{n} \sum_{i+j=k} S^{i} T^{j} x_{n}\right\|+\left\|\frac{1}{L_{n}} \sum_{k=0}^{n} \sum_{i+j=k} S^{i} T^{j} x_{n}-S^{l_{m}}\left(\frac{1}{L_{n}} \sum_{k=0}^{n} \sum_{i+j=k} S^{i} T^{j} x_{n}\right)\right\| \\
& \quad+\left\|S^{l_{m}}\left(\frac{1}{L_{n}} \sum_{k=0}^{n} \sum_{i+j=k} S^{i} T^{j} x_{n}\right)-S^{l_{m}} x\right\| \\
& \leq\left\|x_{n}-\frac{1}{L_{n}} \sum_{k=0}^{n} \sum_{i+j=k} S^{i} T^{j} x_{n}\right\|+\left\|\frac{1}{L_{n}} \sum_{k=0}^{n} \sum_{i+j=k} S^{i} T^{j} x_{n}-S^{l_{m}}\left(\frac{1}{L_{n}} \sum_{k=0}^{n} \sum_{i+j=k} S^{i} T^{j} x_{n}\right)\right\| \\
& \quad+S_{l_{m}}\left\|\frac{1}{L_{n}} \sum_{k=0}^{n} \sum_{i+j=k} S^{i} T^{j} x_{n}-x\right\| \\
& \leq\left\|x_{n}-\frac{1}{L_{n}} \sum_{k=0}^{n} \sum_{i+j=k} S^{i} T^{j} x_{n}\right\|+\left\|\frac{1}{L_{n}} \sum_{k=0}^{n} \sum_{i+j=k} S^{i} T^{j} x_{n}-S^{l_{m}}\left(\frac{1}{L_{n}} \sum_{k=0}^{n} \sum_{i+j=k} S^{i} T^{j} x_{n}\right)\right\| \\
& \quad+S_{l_{m}}\left\|\frac{1}{L_{n}} \sum_{k=0}^{n} \sum_{i+j=k} S^{i} T^{j} x_{n}-x_{n}\right\|+S_{l_{m}}\left\|x_{n}-x\right\| .
\end{aligned}
$$

By Opial's condition, for any $y \in C$ with $y \neq x$, we have

$$
\liminf _{n \rightarrow \infty}\left\|x_{n}-x\right\|<\liminf _{n \rightarrow \infty}\left\|x_{n}-y\right\|
$$

Let $r=\liminf _{n \rightarrow \infty}\left\|x_{n}-x\right\|$ and choose a positive number $\rho$ such that

$$
\rho<\sqrt{r^{2}+\frac{\varepsilon_{0}^{2}}{4}}-r
$$

Then, there exists a subsequence $\left\{x_{n_{p}}\right\}$ of $\left\{x_{n}\right\}$ such that $\lim _{p \rightarrow \infty}\left\|x_{n_{p}}-x\right\|=r$ and $\left\|x_{n_{p}}-x\right\|<$ $r+(\rho / 4)$ for all $p$. By definition of $\left\{s_{l_{m}}\right\}$, there exists a positive integer $m_{0}$ such that

$$
s_{l_{m}}\left\|x_{n_{p}}-x\right\|<r+\frac{\rho}{4}
$$

for all $m>m_{0}$. Since

$$
\lim _{n \rightarrow \infty}\left\|x_{n}-\frac{1}{L_{n}} \sum_{k=0}^{n} \sum_{i+j=k} S^{i} T^{j} x_{n}\right\|=0
$$


and $\left\{s_{l_{m}}\right\}$ is bounded, there exists a positive integer $p_{0}$ such that

$$
\begin{aligned}
\left\|x_{n_{p}}-\frac{1}{L_{n_{p}}} \sum_{k=0}^{n_{p}} \sum_{i+j=k} S^{i} T^{j} x_{n_{p}}\right\| & <\frac{\rho}{4}, \\
S_{l_{m}}\left\|\frac{1}{L_{n_{p}}} \sum_{k=0}^{n_{p}} \sum_{i+j=k} S^{i} T^{j} x_{n_{p}}-x_{n_{p}}\right\| & <\frac{\rho}{4}
\end{aligned}
$$

for all $m$ and $p>p_{0}$. By $\left\{x_{n_{p}}\right\} \subset C$ is bounded and Lemma 2.2, there exist $m_{1}>m_{0}$ and $p_{1}>0$ such that

$$
\left\|\frac{1}{L_{n_{p}}} \sum_{k=0}^{n_{p}} \sum_{i+j=k} S^{i} T^{j} x_{n_{p}}-S^{l_{m_{1}}}\left(\frac{1}{L_{n_{p}}} \sum_{k=0}^{n_{p}} \sum_{i+j=k} S^{i} T^{j} x_{n_{p}}\right)\right\|<\frac{\rho}{4}
$$

for all $p>p_{1}$. By (2.7), (2.10), (2.12), and (2.13), we have

$$
\left\|x_{n_{p}}-S^{l_{m_{1}}} x\right\|<\frac{\rho}{4}+\frac{\rho}{4}+\frac{\rho}{4}+r+\frac{\rho}{4}=r+\rho
$$

for all $p>\max \left\{p_{0}, p_{1}\right\}$. However,

$$
\begin{aligned}
\left\|x_{n_{p}}-\frac{S^{l_{m_{1}}} x+x}{2}\right\|^{2} & =\frac{1}{2}\left\|x_{n_{p}}-S^{l_{m_{1}}} x\right\|^{2}+\frac{1}{2}\left\|x_{n_{p}}-x\right\|^{2}-\frac{1}{4}\left\|S^{l_{m_{1}}} x-x\right\|^{2} \\
& <\frac{(r+\rho)^{2}}{2}+\frac{(r+\rho / 4)^{2}}{2}-\frac{\varepsilon_{0}^{2}}{4} \\
& <(r+\rho)^{2}-\frac{\varepsilon_{0}^{2}}{4} \\
& <r^{2}
\end{aligned}
$$

for all $p>\max \left\{p_{0}, p_{1}\right\}$. This contradicts (2.8). So $\left\{S^{l} x\right\}$ converges strongly to $x$ and then $x \in F(S)$. Similarly, we can get $x \in F(T)$. Hence, $x$ is a common fixed point of $S$ and $T$.

Lemma 2.5 (see [12]). Let $C$ be a bounded closed convex subset of a Hilbert space $H$. The set $D:=$ $\left\{v \in C:\|y-v\|^{2} \leq\|x-v\|^{2}+\langle z, v\rangle+b\right\}$ is convex and closed for given $x, y, z \in C$ and $b \in \mathbb{R}$.

\section{Main results}

In this section, we prove our main theorem.

Theorem 3.1. Let $C$ be a bounded closed convex subset of a Hilbert $H, T$ and $S: C \rightarrow C$ be two commutative asymptotically nonexpansive mappings with asymptotical coefficients $\left\{t_{n}\right\}$ and $\left\{s_{n}\right\}$, respectively. Suppose that $0 \leq \alpha_{n} \leq a$ for all $n$, where $0<a<1$. If $F:=F(T) \cap F(S) \neq \varnothing$, then the sequence generated by (1.5) converges strongly to $P_{F}\left(x_{0}\right)$. 
Proof. Note that $C_{n}$ is convex and closed for all $n \geq 0$ by Lemma 2.5. On the other hand, $Q_{n}$ is convex and closed. So is $C_{n} \cap Q_{n}$.

By definition of $\left\{t_{n}\right\}$ and $\left\{s_{n}\right\}$, there exists $M>0$ such that $\left\|s_{i} t_{j}-1\right\| \leq M$ for all $i, j \geq 0$. On the other hand, for arbitrary $\varepsilon>0$, there exists $N>0$ such that $\left\|s_{i} t_{j}-1\right\|<\varepsilon$ for all $i, j>N$. Hence

$$
\begin{aligned}
\left\|g_{n}-1\right\|= & \left\|\frac{2}{(n+1)(n+2)} \sum_{k=0}^{n} \sum_{i+j=k}\left(s_{i} t_{j}-1\right)\right\| \\
\leq & \frac{2}{(n+1)(n+2)} \sum_{k=0}^{n} \sum_{i+j=k}\left\|s_{i} t_{j}-1\right\| \\
\leq & \frac{2}{(n+1)(n+2)} \sum_{k=0}^{n} \sum_{i+j=k, i \leq N}\left\|s_{i} t_{j}-1\right\|+\frac{2}{(n+1)(n+2)} \sum_{k=0 i+j=k, j \leq N}^{n} \sum_{i \leq N}\left\|s_{i} t_{j}-1\right\| \\
& +\frac{2}{(n+1)(n+2)} \sum_{k=0}^{n} \sum_{i+j=k, i \geq N+1, j \geq N+1}\left\|s_{i} t_{j}-1\right\| \\
< & \frac{2(N+1) M}{(n+2)}+\frac{2(N+1) M}{(n+2)}+\varepsilon .
\end{aligned}
$$

Thus $\lim _{n \rightarrow \infty} g_{n}=1$. Obviously, $\lim _{n \rightarrow \infty} \theta_{n}=0$.

Next, we prove that $F \subset C_{n} \cap Q_{n}$. Indeed, first of all

$$
\begin{aligned}
\left\|y_{n}-p\right\|^{2} & \leq \alpha_{n}\left\|x_{n}-p\right\|^{2}+\left(1-\alpha_{n}\right)\left\|\frac{2}{(n+1)(n+2)} \sum_{k=0}^{n} \sum_{i+j=k} S^{i} T^{j} x_{n}-p\right\|^{2} \\
& \leq \alpha_{n}\left\|x_{n}-p\right\|^{2}+\left(1-\alpha_{n}\right) g_{n}^{2}\left\|x_{n}-p\right\|^{2} \\
& =\left\|x_{n}-p\right\|^{2}+\left(1-\alpha_{n}\right)\left(g_{n}^{2}\left\|x_{n}-p\right\|^{2}-\left\|x_{n}-p\right\|^{2}\right) \\
& \leq\left\|x_{n}-p\right\|^{2}+\theta_{n}
\end{aligned}
$$

for all $p \in F$. So $F \subset C_{n}$. It suffices to show that $F \subset Q_{n}$ for all $n \geq 0$. We prove this by induction. For $n=0$, we have $F \subset C=Q_{0}$. Assume that $F \subset Q_{n}$. Since $x_{n+1}$ is the projection of $x_{0}$ onto $C_{n} \cap Q_{n}$, we have

$$
\left\langle x_{n+1}-z, x_{0}-x_{n+1}\right\rangle \geq 0 \quad \forall z \in C_{n} \bigcap Q_{n}
$$

As $F \subset C_{n} \cap Q_{n}$, (3.3) holds for all $z \in F$, in particular. This together with the definition of $Q_{n+1}$ implies that $F \subset Q_{n+1}$. Hence, $F \subset C_{n} \cap Q_{n}$ for all $n \geq 0$.

We will show that $\left\|x_{n+1}-x_{n}\right\| \rightarrow 0$ as $n \rightarrow \infty$. By the definition of $Q_{n}$, we have that $x_{n}=$ $P_{Q_{n}}\left(x_{0}\right)$. It follows from $x_{n+1} \in C_{n} \cap Q_{n} \subset Q_{n}$ that $\left\|x_{n}-x_{0}\right\| \leq\left\|x_{n+1}-x_{0}\right\|$. This shows that the sequence $\left\{\left\|x_{n}-x_{0}\right\|\right\}$ is increasing. Since $C$ is bounded, we obtain that $\lim _{n \rightarrow \infty}\left\|x_{n}-x_{0}\right\|$ exists. 
Notice again that from $x_{n}=P_{Q_{n}}\left(x_{0}\right)$ and $x_{n+1} \in Q_{n}$, we have $\left\langle x_{n+1}-x_{n}, x_{n}-x_{0}\right\rangle \geq 0$. Hence

$$
\begin{aligned}
\left\|x_{n+1}-x_{n}\right\|^{2} & =\left\|\left(x_{n+1}-x_{0}\right)-\left(x_{n}-x_{0}\right)\right\|^{2} \\
& =\left\|x_{n+1}-x_{0}\right\|^{2}+\left\|x_{n}-x_{0}\right\|^{2}-2\left\langle x_{n+1}-x_{0}, x_{n}-x_{0}\right\rangle \\
& =\left\|x_{n+1}-x_{0}\right\|^{2}-\left\|x_{n}-x_{0}\right\|^{2}-2\left\langle x_{n+1}-x_{0}-\left(x_{n}-x_{0}\right), x_{n}-x_{0}\right\rangle \\
& =\left\|x_{n+1}-x_{0}\right\|^{2}-\left\|x_{n}-x_{0}\right\|^{2}-2\left\langle x_{n+1}-x_{n}, x_{n}-x_{0}\right\rangle \\
& \leq\left\|x_{n+1}-x_{0}\right\|^{2}-\left\|x_{n}-x_{0}\right\|^{2} \\
& \longrightarrow 0 \quad(n \longrightarrow \infty) .
\end{aligned}
$$

Now we claim that $\left\|(2 /(n+1)(n+2)) \sum_{k=0}^{n} \sum_{i+j=k} S^{i} T^{j} x_{n}-x_{n}\right\| \rightarrow 0$ as $n \rightarrow \infty$. By the definition of $y_{n}$, we have

$$
\begin{aligned}
& \left\|\frac{2}{(n+1)(n+2)} \sum_{k=0}^{n} \sum_{i+j=k} S^{i} T^{j} x_{n}-x_{n}\right\| \\
& \quad=\frac{1}{1-\alpha_{n}}\left\|y_{n}-x_{n}\right\| \\
& \quad \leq \frac{1}{1-\alpha_{n}}\left(\left\|y_{n}-x_{n+1}\right\|+\left\|x_{n+1}-x_{n}\right\|\right) \\
& \quad \leq \frac{1}{1-a}\left(\left\|y_{n}-x_{n+1}\right\|+\left\|x_{n+1}-x_{n}\right\|\right) .
\end{aligned}
$$

Since $x_{n+1} \in C_{n},\left\|y_{n}-x_{n+1}\right\|^{2} \leq\left\|x_{n}-x_{n+1}\right\|^{2}+\theta_{n} \rightarrow 0$ as $n \rightarrow \infty$. So $\left\|y_{n}-x_{n+1}\right\| \rightarrow 0$ as $n \rightarrow \infty$. This implies that

$$
\left\|\frac{2}{(n+1)(n+2)} \sum_{k=0}^{n} \sum_{i+j=k} S^{i} T^{j} x_{n}-x_{n}\right\| \longrightarrow 0 \quad(n \longrightarrow \infty) .
$$

Since $C$ is bounded closed convex, $\omega_{w}\left(x_{n}\right) \neq \varnothing$. It follows from (3.6) and Lemma 2.4 that $\omega_{w}\left(x_{n}\right) \subset F$. By the definition of $Q_{n}$, we have that $\left\|x_{n}-x_{0}\right\| \leq\left\|P_{F}\left(x_{0}\right)-x_{0}\right\|$ for all $n \geq 0$. It follows from the weak lower semi-continuity of the norm that $\left\|w-x_{0}\right\| \leq\left\|P_{F}\left(x_{0}\right)-x_{0}\right\|$ for all $w \in \omega_{w}\left(x_{n}\right)$. Since $\omega_{w}\left(x_{n}\right) \subset F$, we have $w=P_{F}\left(x_{0}\right)$ for all $w \in \omega_{w}\left(x_{n}\right)$. Thus $\omega_{w}\left(x_{n}\right)=\left\{P_{F}\left(x_{0}\right)\right\}$. Then, $\left\{x_{n}\right\}$ converges to $P_{F}\left(x_{0}\right)$ weakly. By the fact

$$
\begin{aligned}
\left\|x_{n}-P_{F}\left(x_{0}\right)\right\|^{2} & =\left\|x_{n}-x_{0}+x_{0}-P_{F}\left(x_{0}\right)\right\|^{2} \\
& =\left\|x_{n}-x_{0}\right\|^{2}+\left\|x_{0}-P_{F}\left(x_{0}\right)\right\|^{2}+2\left\langle x_{n}-x_{0}, x_{0}-P_{F}\left(x_{0}\right)\right\rangle \\
& \leq 2\left(\left\|P_{F}\left(x_{0}\right)-x_{0}\right\|^{2}+\left\langle x_{n}-x_{0}, x_{0}-P_{F}\left(x_{0}\right)\right\rangle\right) \\
& \longrightarrow 0 \quad(n \longrightarrow \infty),
\end{aligned}
$$

we have $\left\{x_{n}\right\}$ converges to $P_{F}\left(x_{0}\right)$ strongly. This completes the proof. 
The following corollary follows from Theorem 3.1.

Corollary 3.2. Let $C$ be a bounded closed convex subset of a Hilbert $H, T$ and $S: C \rightarrow C$ be two commutative nonexpansive mappings. Suppose that $0 \leq \alpha_{n} \leq a$ for all $n$, where $0<a<1$. If $F:=F(T) \cap F(S) \neq \varnothing$, then the sequence $\left\{x_{n}\right\}$ generated by

$$
\begin{aligned}
x_{0} & \in C \text { chosen arbitrarily, } \\
y_{n} & =\alpha_{n} x_{n}+\left(1-\alpha_{n}\right) \frac{2}{(n+1)(n+2)} \sum_{k=0}^{n} \sum_{i+j=k} S^{i} T^{j} x_{n}, \\
C_{n} & =\left\{v \in C:\left\|y_{n}-v\right\|^{2} \leq\left\|x_{n}-v\right\|^{2}\right\}, \\
Q_{n} & =\left\{v \in C:\left\langle x_{n}-v, x_{0}-x_{n}\right\rangle \geq 0\right\}, \\
x_{n+1} & =P_{C_{n} \cap Q_{n}}\left(x_{0}\right),
\end{aligned}
$$

converges strongly to $P_{F}\left(x_{0}\right)$.

\section{Acknowledgment}

This work is supported by National Natural Science Foundation of China (10771173).

\section{References}

[1] K. Goebel and W. A. Kirk, "A fixed point theorem for asymptotically nonexpansive mappings," Proceedings of the American Mathematical Society, vol. 35, no. 1, pp. 171-174, 1972.

[2] H. Ishihara and W. Takahashi, "A nonlinear ergodic theorem for a reversible semigroup of Lipschitzian mappings in a Hilbert space," Proceedings of the American Mathematical Society, vol. 104, no. 2, pp. 431-436, 1988.

[3] Z. Opial, "Weak convergence of the sequence of successive approximations for nonexpansive mappings," Bulletin of the American Mathematical Society, vol. 73, no. 4, pp. 591-597, 1967.

[4] S. Ishikawa, "Fixed points by a new iteration method," Proceedings of the American Mathematical Society, vol. 44, no. 1, pp. 147-150, 1974.

[5] W. R. Mann, "Mean value methods in iteration," Proceedings of the American Mathematical Society, vol. 4, no. 3, pp. 506-510, 1953.

[6] J. Schu, "Weak and strong convergence to fixed points of asymptotically nonexpansive mappings," Bulletin of the Australian Mathematical Society, vol. 43, no. 1, pp. 153-159, 1991.

[7] T. Shimizu and W. Takahashi, "Strong convergence to common fixed points of families of nonexpansive mappings," Journal of Mathematical Analysis and Applications, vol. 211, no. 1, pp. 71-83, 1997.

[8] T.-H. Kim and H.-K. Xu, "Strong convergence of modified Mann iterations for asymptotically nonexpansive mappings and semigroups," Nonlinear Analysis: Theory, Methods \& Applications, vol. 64, no. 5, pp. 1140-1152, 2006.

[9] N. Shioji and W. Takahashi, "Strong convergence theorems for asymptotically nonexpansive semigroups in Hilbert spaces," Nonlinear Analysis: Theory, Methods \& Applications, vol. 34, no. 1, pp. 87-99, 1998.

[10] Y. Haugazeau, Sur les inéquations variationnelles et la minimisation de fonctionnelles convexes, Ph.D. thesis, Université de Paris, Paris, France, 1968.

[11] S. Plubtieng and K. Ungchittrakool, "Strong convergence of modified Ishikawa iteration for two asymptotically nonexpansive mappings and semigroups," Nonlinear Analysis: Theory, Methods $\mathcal{E}$ Applications, vol. 67, no. 7, pp. 2306-2315, 2007.

[12] C. Martinez-Yanes and H.-K. Xu, "Strong convergence of the CQ method for fixed point iteration processes," Nonlinear Analysis: Theory, Methods \& Applications, vol. 64, no. 11, pp. 2400-2411, 2006. 


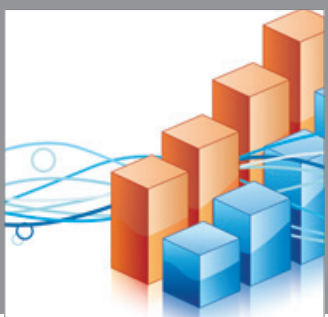

Advances in

Operations Research

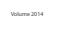

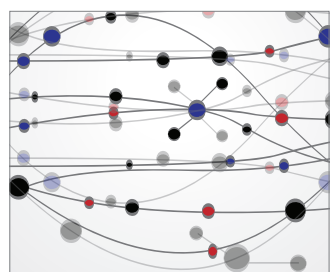

\section{The Scientific} World Journal
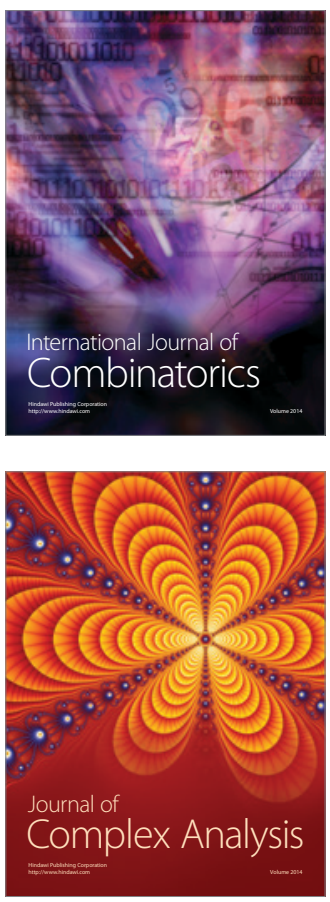

International Journal of

Mathematics and

Mathematical

Sciences
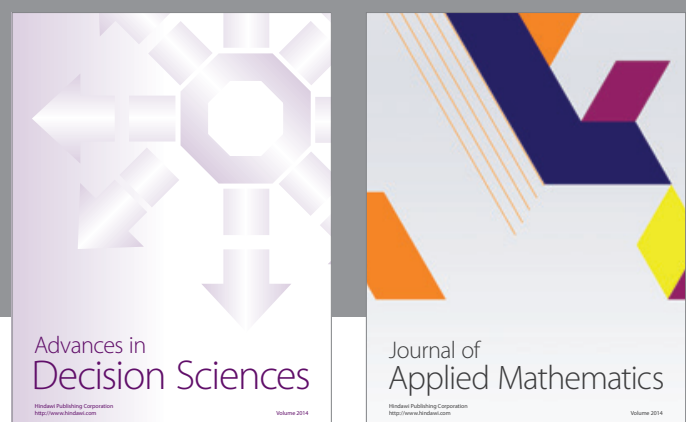

Journal of

Applied Mathematics
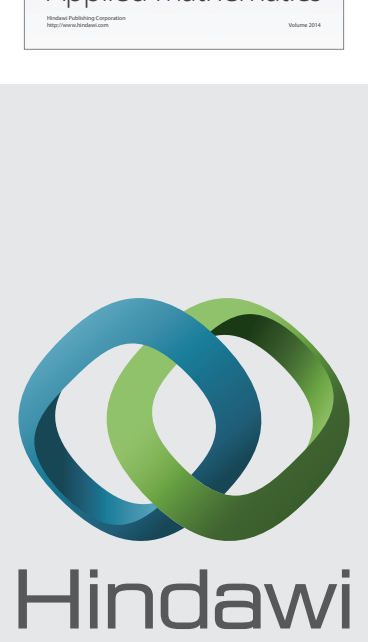

Submit your manuscripts at http://www.hindawi.com
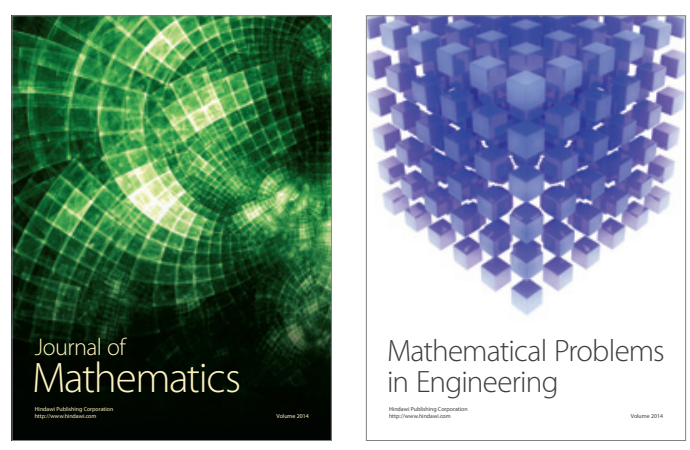

Mathematical Problems in Engineering
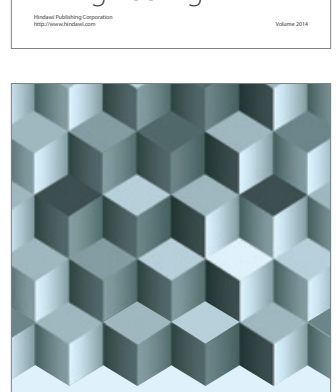

Journal of

Function Spaces
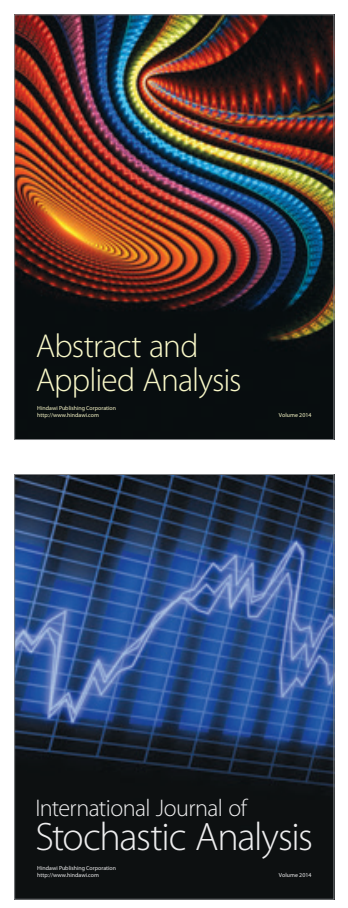

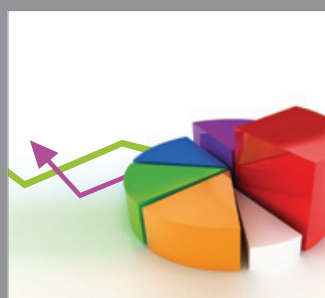

ournal of

Probability and Statistics

Promensencen
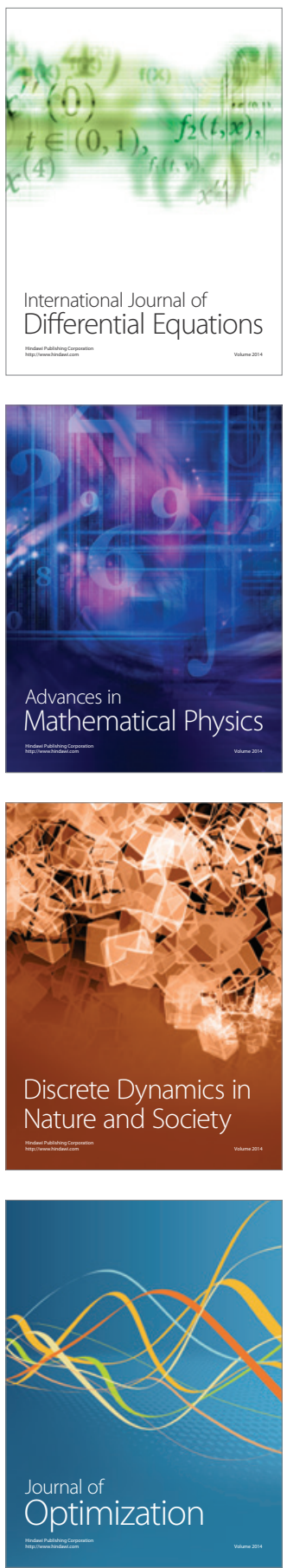